\title{
Improvement of an Isolation Medium for Actinomycetes
}

\author{
Jinhua Zhang \\ College of Life Science, Hebei University \\ Key Lab of Microbial Diversity Research and Application of Hebei Prov., Baoding 071002, China \\ E-mail: zhangjinhuadai@163.com \\ Liping Zhang (Corresponding author) \\ College of Life Science, Hebei University \\ Key Lab of Microbial Diversity Research and Application of Hebei Prov., Baoding 071002, China \\ Tel: 86-312-507-9696 E-mail: zhlping@hbu.edu.cn
}

Received: December 29, 2010

Accepted: March 7, 2011

doi:10.5539/mas.v5n2p124

This research was financially supported by National Science Foundation of China titled "studies on the actionmycetes diversity in Yan Mountains (Grant No. 30970010)" and Hebei Province Basic Research Project titled "Hebei microbial resource base information database" (Grant No. 10967146 D).

\begin{abstract}
By comparing differences among the effects of several isolation mediums on soil actinomycetes, we attempted to find a isolation medium that could result in actionomycetes with high diversity. Soil samples were isolated by the dilution plateing method, and genomic DNA was extracted using phenol-chloroform method. After amplification by $16 \mathrm{~S}$ rDNA PCR, PCR products were sequenced and undertaken phylogenetic analysis in order to determine the ownership of isolates. The results showed that the isolated strains belonged to 15 genuses; as for the established medium in the present paper, ZSSE was easier to isolate rare actiomycetes with rich diversity, and could replace routine agars such as Gause`s No.1, HV and ISP5; CHV was easier to isolate micromonospora.
\end{abstract}

Keywords: Actinomycetes, Separation medium, Species diversity

Actinomycetes were bacterium that could form branches, and such branches were mycelium formed by thallus. They were generally saprophytic, and widely distributed in nature, and only a small number of them coexisted with plants. They distributed in soil, air and water in the form of spores or mycelium, especially in slightly alkaline or neutral soil with low water content and rich organic matters.

Ever since Wakksman and Umezwa found the usage diversity of actinomycetes, actionmycetes have been applied as a producing strain for antibiotics, vitamins, enzymes and enzyme inhibitors, and thus have been a microbial population with huge application values.

Acquiring new strains was a necessary condition for modern actinomycetes resource development, and therefore, studies on the separation methods tended to be very critical. There have been great progresses made in selective isolation of rate actinomycetes by researchers at home or abroad in recent years (Jiang, 2006, PP. 181-183; Li, 2002, PP. 105-108; Li, 2003, PP. 114-117; Si, 2004, PP. 61-65). However, a large number of actinomycetes couldn't be separated, and as seen from modern molecular biology studies, there were at least $90 \%$ unknown actinomycetes that couldn't be isolated existed in nature (Duan, 2007, PP. 32-33). Accordingly, in the present paper, we investigated the differences among effects of several mediums on isolating soil actinomycetes, and attempted to find a separation medium for isolating actinomycetes with high species diversity.

\section{Materials and methods}

\subsection{Materials}

1.1.1 Soil

Soil samples were sampled from different regions in Shanxi Province and all collected $15 \mathrm{~cm}$ away from the earth's surface (Table 1).

1.1.2 Medium

Preparation of soil extracts: $400 \mathrm{~g}$ dried soil without miscellaneous stones were added to $960 \mathrm{~mL}$ tap water, 
completely agitated, and sterilized by autoclaving at $121^{\circ} \mathrm{C}$. After standing a while, the resultant solution was filtered twice by filter cloth and filter paper subsequently, and sterilized at $121^{\circ} \mathrm{C}$ for $20 \mathrm{~min}$. The filtrate was used to prepare soil leaching juice agar medium.

Trace salt solution: $0.1 \mathrm{~g} \mathrm{FeSO}_{4}, 0.1 \mathrm{~g} \mathrm{MnCl}_{2}, 0.1 \mathrm{~g} \mathrm{ZnSO}$, and $100 \mathrm{~mL}$ distilled water.

Soil extracts agar: $5 \mathrm{~g}$ peptone, $3 \mathrm{~g}$ beef extract, $1000 \mathrm{~mL}$ soil extracts, $10 \mathrm{~g}$ agar, $\mathrm{pH} 7.2$.

Glycerol-asparagine agar: $1 \mathrm{~g}$ asparagine, $10 \mathrm{~g}$ glycerol, $1 \mathrm{~g} \mathrm{~K} \mathrm{HPO}_{4}, 1 \mathrm{~mL}$ trace salt solution, $10 \mathrm{~g}$ agar, $1000 \mathrm{~mL}$ distilled water, $\mathrm{pH} 7.2$.

Gause`s No.1 medium: $20 \mathrm{~g}$ soluble starch, $1 \mathrm{~g} \mathrm{KNO}$, $0.5 \mathrm{~g} \mathrm{NaCl}, 0.5 \mathrm{~g} \mathrm{~K}_{2} \mathrm{HPO}_{4}, 0.5 \mathrm{~g} \mathrm{MgSO}_{4}, 0.01 \mathrm{~g} \mathrm{FeSO}_{4}, 10 \mathrm{~g}$ agar, $1000 \mathrm{~mL}$ distilled water, $\mathrm{pH} 7.2$;

HV agar: $1 \mathrm{~g}$ humic acid, $1.7 \mathrm{~g} \mathrm{KCl}, 0.5 \mathrm{~g} \mathrm{Na}_{2} \mathrm{HPO}_{4}, 0.5 \mathrm{~g} \mathrm{MgSO}_{4}, 0.02 \mathrm{~g} \mathrm{CaCO}_{3}, 0.01 \mathrm{~g} \mathrm{FeSO}, 1 \mathrm{~mL} \mathrm{~V}_{\mathrm{B}}$ stock solution, $10 \mathrm{~g}$ agar, $1000 \mathrm{~mL}$ distilled water, $\mathrm{pH} 7.2,\left(\mathrm{~V}_{\mathrm{B}}\right.$ stock solution: $50 \mathrm{mgV}_{\mathrm{B} 1}, \mathrm{~V}_{\mathrm{B} 2}$, niacin , $\mathrm{V}_{\mathrm{B} 6}$, D-calcium pantothenate, inositol, and PABA (para amino acid), $25 \mathrm{mg}$ Biotin, and $100 \mathrm{~mL}$ distilled water);

According to years' laboratory experiences of isolating actinomycetes under different environments, we created CHV (Complex HV Agar) and ZSSE (Zhang'Starch Soil Extract Agar) mediums and first used them in the present paper.

CHV agar: $0.5 \mathrm{~g}$ humic acid, $10 \mathrm{~g}$ agar, $1000 \mathrm{~mL}$ soil leaching juice, $1 \mathrm{~mL} \mathrm{~V}_{\mathrm{B}}$ stock solution, $\mathrm{pH} 7.2$;

ZSSE agar: $5 \mathrm{~g}$ soluble starch, $1 \mathrm{~g} \mathrm{KNO}, 1000 \mathrm{~mL}$ soil extracts , $10 \mathrm{~g}$ agar, $\mathrm{pH} 7.2$.

$50 \mathrm{mg} / \mathrm{L}$ nalidixic acid and $100 \mathrm{mg} / \mathrm{L}$ nystatin were added to each medium as inhibitor, respectively.

\subsection{Methods}

\subsubsection{Soil treatment}

Soil samples were dried in ventilated dark room for 7 days.

\subsubsection{Separation method}

$50 \mathrm{mg} / \mathrm{L}$ nalidixic acid and $100 \mathrm{mg} / \mathrm{L}$ nystatin were added to six mediums as an inhibitor of bacteria, viz. HV, CHV, ZSSE, Gause's No.1, soil extracts agar and glycerol-asparagine. Samples were diluted in a gradient, and $10^{-6}$ and $10^{-7}$ of stock solution was coated in the plates. the plates were incubated at $28{ }^{\circ} \mathrm{C}$. Actinomycetes colonies with different forms were obtained at different periods, and colonies of all separated plated were counted.

\subsubsection{Extraction of genomic DNA}

Genomic DNA of actinomycetes was extracted using phenol-chloroform method (Marmur, 1961, PP. 208-218).

\subsubsection{PCR amplification of 16S rDNA sequence}

Using 16S rDNA sequences universal primers 27f (5'-AGAGTTTGATCMTGGCTC AG-3') and 1525r (5'-AGAAAGGAGGTGWTCC ARCC-3') as primers (Lane, 1991, PP. 115-175), 16S rDNA was undertaken PCR amplification, and PCR products were sequenced.

\subsubsection{Phylogenetic analysis}

Sequencing results were compared using BLAST method, and phylogenetic trees were constructed using neighbor joining module of software MEGA4.1 in order to analyze phylogenetic relationships of strains (Tamura, 2007, PP. 1596-1599; Saitou, 1987, PP. 406-425).

\section{Results and Analysis}

\subsection{Separation effects of mediums}

As seen from Figure 1 and Table 2, among six mediums, the number of non-actinomycetes in plates from Gause`s No.1 was the least while the size of colony was biggest. The number of non-actinomycetes in plates from $\mathrm{HV}$ and $\mathrm{CHV}$ was the most. The number of actinomycetes in plates from ZSSE was the most, and CHV followed. Aerial mycelium of actinomycetes in soil extracts agar and glycerol-asparagine grew slowly, and several colonies were tough to distinguish from others.

\subsection{Phylogenetic analysis}

134 strains with greater morphological difference were selected from the obtained 232 strains to undertake sequence, and results indicated as follows: 68 strains of Streptomyces, 23 Micromonospora, 11 Nocardia, 3 Actinomadura, 9 Promicromonospora, 2 Pseudonocardia, 2 Rhodococcus, 4 Saccharothrix, 5 Nonomuraea, 2 
Cellulomonas, 1 Jiangella, 1 Gordonia, 1 Cellulosimicrobium, 1 Kribblla, and 1 Williamsia. Results were listed in Table 3 in detail.

\section{Discussions}

Although there were great differences in genus among the obtained rare actinomycetes resulted from different soil samples, genus diversity of the isolated actinomycetes increased with the enrichment of vegetations. Generally, the strains isolated from Gause's No.1 were mainly common Streptomyces, other rate actinomycetes were tough to isolate, and other bacteria excluding actinomycetes grew less; the strains isolated from ZSSE, HV, $\mathrm{CHV}$, soil extracts agar and glycerol-asparagine were mainly other bacteria, and such bacteria could be mainly gram-positive. Accordingly, the added inhibitors failed to work effectively; the strains isolated from glycerol-asparagine were mostly Streptomyces, the resultant colonies formed aerial mycelium slowly, and thus it was hard to distinguish the rare actinomycetes; genus from HV and had many sorts of actinomycetes, and especially for soil extracts agar, the number of bacteria was so higher that large colony was easy to select other bacteria after long incubation; CHV could enhance the number and diversity of Micromonospora, but decreased the diversity of other actinomycetes; ZSSE resulted in a rich species diversity of actinomycetes with the largest sorts and number of rare actinomycetes, and its colony size was uniform. The growth of bacteria couldn't basically hamper the selection of actinomycetes colonies.

Taken together, ZSSE medium established in the present paper possessed the nutritional characteristics of both Gause's No.1 and soil leaching juice, and was easier to isolate rare actinomycetes with rich diversity. It overcame the shortcomings that general mediums couldn't take both specificity and diversity into account, and could basically replace Gause's No.1, HV and glycerol-asparagine to isolate actinomycetes; compared to soil extracts agar, bacteria biomass was less, and it was easier to select actinomycetes. CHV medium was more suitable for the separation of micromonospora.

\section{References}

Duan, S.R. (2007). Approaches for selective isolation of rare actinomycetes by pretreatment. Anhui Agricultural Science Bulletin, 13(23):32-33.

Jiang, Y., Duan, S.R., \& Tang, S.K., et al. (2006). Isolation methods of rare actinomycetes. Microbiology, 33(1):181-183.

Lane, D.J. (1991). 16S/23S rRNA Sequencing [M]/Stackebrandte E, Goodfellow M. Nucleic acid techniques in bacterial systematics. Chichester, England: Academic Press, 115-175.

Li, Y.V., Terekhova, L.P., \& Gapochka, M.G. (2002). Isolation of actinomycetes from soil using extremely high frequency radiation. Microbiology, 71(1):105-108.

Li, Y.V., Terekhova, L.P., \&, Alferova, I.V., et al. (2003). The application of succession analysis in combination with EHF irradiation to the selective isolation of actionmycetes from soil. Microbiology, 72(1):114-117.

Marmur, J. (1961). A procedure for the isolation of deoxyribonucleic acid from microorganisms. J. Mol. Biol, 3:208-218.

Saitou, N., \& Neim. (1987). The neighbour joining method a new method for constructing phylogenetic trees. Mol. Biol. Evol, 4:406-425.

Si, M.R., Xue, Q.H., \& Lai, H.X. (2004). Studies on selection of the isolation medium for actinomycetes and inhibition methods to miscellaneous microorganism. Microbiology, 33(2):61-65.

Tamura, K., Dudley, J., \& Neim, et al. (2007). MEGA4 molecular evolutionary genetics analysis (MEGA) software version 4.0. Mol. Biol. Evol., 24:1596-1599.

Table 1. Source of the soil samples

\begin{tabular}{|c|c|c|c|}
\hline Serial number & Region & Vegetation & Date \\
\hline S1 & Yuncheng & Cropland & 2009.6 \\
\hline S2 & Jianbei & Secondary forest & 2009.6 \\
\hline S3 & Linfen & Secondary forest & 2009.6 \\
\hline S4 & Changsong & Cropland & 2009.6 \\
\hline S5 & Linfen & Shrub & 2009.6 \\
\hline S6 & Linfen & Meadow & 2009.6 \\
\hline S7 & Yuncheng & Cropland & 2009.6 \\
\hline S8 & Linfen & Secondary forest & 2009.6 \\
\hline
\end{tabular}


Table 2. Effects of 6 medium on isolating actinomycetes

\begin{tabular}{|c|l|l|l|l|l|l|}
\hline Quantity & $\begin{array}{c}\text { Gause`s } \\
\text { No.1 }\end{array}$ & ZSSE & HV & CHV & Glycerol-asparagine & $\begin{array}{c}\text { soil extracts } \\
\text { agar }\end{array}$ \\
\hline $\begin{array}{c}\text { cfu } \\
\left(10^{6} / \mathrm{mL}\right)\end{array}$ & 1.78 & 6.22 & 4.1 & 5.56 & 3 & 3.66 \\
\hline
\end{tabular}

Table 3. Phylogeny analysis of the isolates

\begin{tabular}{|l|c|c|c|c|c|c|}
\hline \multirow{2}{*}{\multicolumn{1}{|c|}{ Genus of isolates }} & \multicolumn{7}{|c|}{ Strain number } \\
\cline { 2 - 7 } & 1 & 2 & 3 & 4 & 5 & 6 \\
\hline Streptomyces & 4 & 18 & 7 & 7 & 20 & 12 \\
\hline Micromonospora & 4 & 4 & 3 & 6 & 3 & 3 \\
\hline Nocardia & 0 & 3 & 2 & 2 & 0 & 4 \\
\hline Actinomadura & 0 & 0 & 0 & 2 & 0 & 1 \\
\hline Promicromonospora & 1 & 1 & 2 & 3 & 1 & 1 \\
\hline Pseudonocardia & 0 & 1 & 0 & 1 & 0 & 0 \\
\hline Rhodococcus & 0 & 1 & 1 & 0 & 0 & 0 \\
\hline Saccharothrix & 0 & 3 & 0 & 0 & 1 & 0 \\
\hline Nonomuraea & 1 & 1 & 1 & 0 & 0 & 2 \\
\hline Cellulomonas & 0 & 1 & 0 & 0 & 0 & 1 \\
\hline Jiangella & 0 & 1 & 0 & 0 & 0 & 0 \\
\hline Gordonia & 0 & 1 & 0 & 0 & 0 & 0 \\
\hline Cellulosimicrobium & 0 & 0 & 0 & 0 & 0 & 1 \\
\hline Kribblla & 0 & 0 & 0 & 0 & 1 & 0 \\
\hline Williamsia & 0 & 0 & 1 & 0 & 0 & 0 \\
\hline Sum & 10 & 35 & 17 & 21 & 26 & 25 \\
\hline
\end{tabular}

Note: 1, ZSSE; 2, Gause`s No.1; 3, soil extracts agar; 4, glycerol-asparagine; 5, HV; 6, CHV
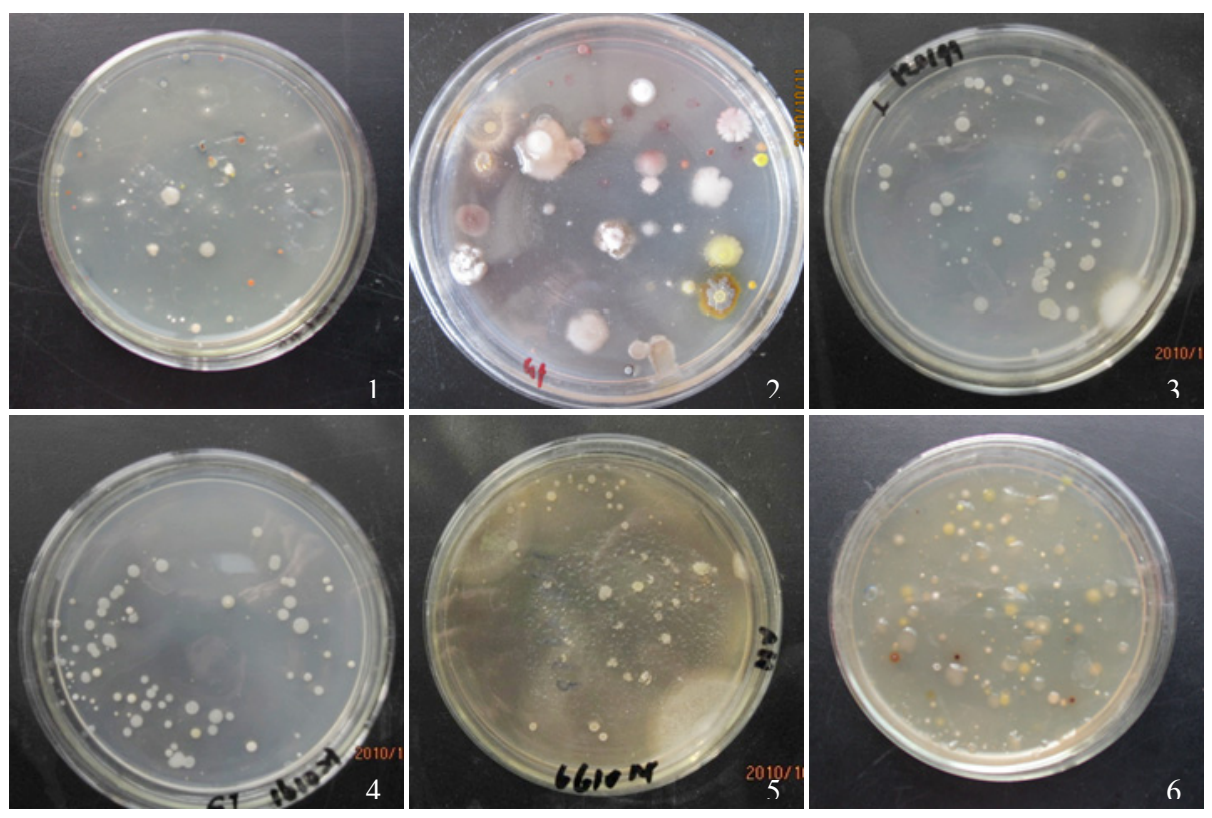

Figure 1. Colonies in 6 isolated mediums

Note: 1, ZSSE; 2, Gause`s No.1 No.1; 3, soil extracts agar; 4, glycerol-asparagine; 5, HV; 6, CHV 